\title{
Platinum-catalysed cinnamaldehyde hydrogenation in continuous flow
}

Lee J. Durndell, ${ }^{a}$ Karen Wilson ${ }^{\mathrm{a}}$ and Adam F. Lee $\mathrm{a}^{\mathrm{a}^{*}}$

Platinum is one of the most widely used hydrogenation catalysts. Here we describe the translation of batch reactions to continuous flow, affording tunable $\mathrm{C}=0$ versus $\mathrm{C}=\mathrm{C}$ hydrogenation over $\mathrm{a}$ $\mathrm{Pt} / \mathrm{SiO}_{2}$ catalyst, resulting in high steady state activity and singlepass yields in the selective hydrogenation of cinnamaldehyde to cinnamyl alcohol under mild conditions. Negligible catalyst deactivation occurs under extended flow operation due to removal of reactively-formed poisons from the reaction zone. Process intensification imparts a four-fold enhancement in cinnamyl alcohol productivity.

Chemoselectivity underpins $21^{\text {st }}$ century catalysis, ${ }^{1,} \quad 2$ permitting the targeted modification of specific functional groups within complex starting materials, ${ }^{3-7}$ notably from biomass-derived feedstocks. ${ }^{8}$ Catalytic hydrogenation of organic compounds possessing multiple unsaturated bonds such as $\alpha, \beta$-unsaturated aldehydes is particularly challenging, ${ }^{9-}$ 11 necessitating active sites able to discriminate and preferentially activate closely related moieties. Platinum is widely employed in heterogeneously catalysed hydrogenation of diverse functional groups including $C=C,{ }^{12} C \equiv C^{13} \quad C=O, 13$ $\mathrm{C} \equiv \mathrm{N},{ }^{14} \mathrm{NO}_{2}{ }^{15}$ and aromatics. ${ }^{15}$ The selective hydrogenation of allylic and benzylic aldehydes to unsaturated alcohols is a commercially important industrial process within the flavour, fragrance, agrochemical and pharmaceutical sectors, 9,16 in which active and selective heterogeneous catalysts for such transformations are essential to circumvent the greater thermodynamic stability of $\mathrm{C}=\mathrm{O}$ relative to $\mathrm{C}=\mathrm{C}$ bonds. ${ }^{9}$

The liquid phase, selective hydrogenation of cinnamaldehyde (CinnALD) to cinnamyl alcohol (CinnOH) illustrated in Scheme 1 is of significant interest due to the widespread use of this allylic alcohol in perfumes and flavourants. ${ }^{16-19}$ Platinum is a promising catalyst for this challenging reaction, in which hydrogenation of the $\mathrm{C}=\mathrm{C}$ bond is both kinetically and

a. European Bioenergy Research Institute, Aston University, Birmingham B4 7ET, UK Electronic Supplementary Information (ESI) available: Details of catalyst synthesis and characterisation, and reaction conditions for batch and continuous flow cinnamaldehyde hydrogenation. See DOI: 10.1039/x0xx00000x thermodynamically more favourable than the $\mathrm{C}=\mathrm{O}$ function, ${ }^{20}$ and hence the influence of the physicochemical properties of

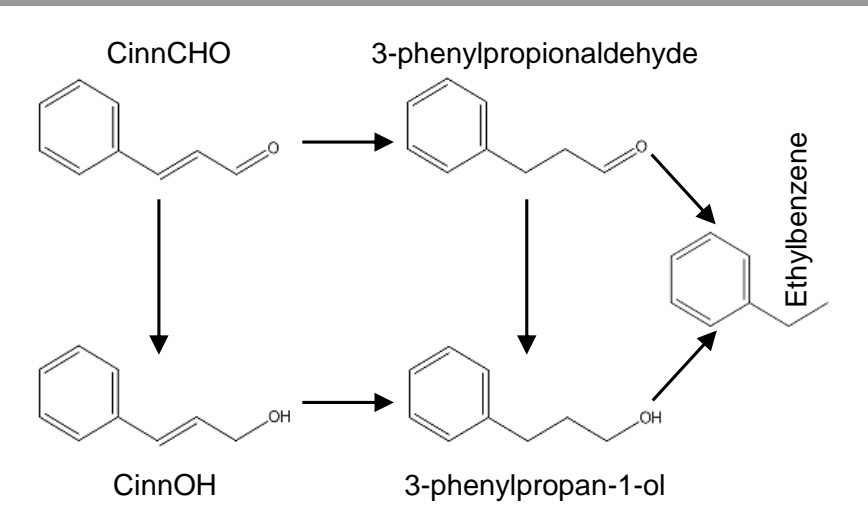

Scheme 1. Principal reaction pathways operating in the Pt-catalysed liquid phase hydrogenation of cinnamaldehyde.

platinum nanoparticles is a topic of much intensive recent investigation in batch reactors. Particle size effects upon CinnOH selectivity have proved controversial, with oleic acid/oleylamine stabilised mono- and bimetallic colloidal Pt nanoparticles reported to exhibit a strong size dependence of CinnOH selectivity, with low coordination sites favoring $\mathrm{C}=\mathrm{C}$ hydrogenation, ${ }^{21,} 22$ whereas $\mathrm{Zhu}$ and Zaera reported that $\mathrm{CinnOH}$ selectivity was insensitive to the size of silica supported Pt nanoparticles albeit over a narrow size range. ${ }^{23}$ Guo et al have shown that confinement of Pt nanoclusters within the cavity of metal-organic frameworks also promotes CinnOH selectivity; with steric constraints on CinnALD believed to hinder $\mathrm{C}=\mathrm{C}$ planar adsorption with consequent preferential $\mathrm{C}=\mathrm{O}$ activation. ${ }^{24}$ Kinetics of CinnALD hydrogenation are also a function of support properties ${ }^{25}$ and hydrogenation pressure. We recently reported a detailed mechanistic study of the structural and electronic factors controlling the liquid phase hydrogenation of cinnamaldehyde and related benzylic aldehydes over fumed $\mathrm{SiO}_{2}$ and mesoporous SBA-15 supported Pt nanoparticles. ${ }^{26}$ Kinetic mapping revealed cinnamaldehyde hydrogenation is structure-insensitive over metallic platinum, proceeding with a common Turnover Frequency (TOF) 
independent of precursor, particle size or support architecture, while selectivity to $\mathrm{CinnOH}$ is highly structure sensitive. Large nanoparticles and high hydrogen pressures favored $\mathrm{C}=\mathrm{O}$ over $\mathrm{C}=\mathrm{C}$ hydrogenation due to molecular surface crowding, while in situ ATR-IR highlighted the role of support polarity in enhancing $\mathrm{C}=\mathrm{O}$ hydrogenation.

Catalytic hydrogenations are traditionally conducted in stirred batch reactors, presenting challenges in respect of the low hydrogen solubility in most solvents, which results in mass transfer limitations. ${ }^{27,} 28$ These are typically offset through the use of high pressures of up to 100 bar, which increases the associated explosion risks. Small-scale microreactors offer a safer, alternative approach to high-pressure hydrogenations with molecular hydrogen, and in conjunction with continuous flow processing offers significant benefits compared to batch processes, related to the unique gas-liquid-solid triphasic reaction conditions present in such transformations, improved safety, and process intensification. ${ }^{29}$ In recent years the chemical and pharmaceutical sectors have thus targeted a switchover from batch to continuous operation to achieve atom economical, and scalable organic synthesis. ${ }^{30,31}$ To date, the continuous, liquid phase selective hydrogenation of cinnamaldehyde has only been the subject of two peerreviewed studies, wherein the focus was evaluating the suitability of either pellet string ${ }^{32}$ or high-pressure membrane ${ }^{33}$ reactor designs for industrial chemical synthesis. In both cases, the respective $\mathrm{Pd} / \mathrm{Al}_{2} \mathrm{O}_{3}$ and $\mathrm{Pd} / \mathrm{MCM}-41$ catalysts employed were only selective to hydrocinnamaldehyde, and only studied at high pressures $>10$ bar. In contrast, $\mathrm{Pt} / \mathrm{SiO}_{2}$ and $\mathrm{Pt} / \mathrm{SBA}-15$ catalysts are moderately selective to desirable $\mathrm{CinnOH}$ at lower pressures, ${ }^{26}$ but are prone to on-stream deactivation in batch, and exhibit strong time selectivity variations. Here we demonstrate that continuous flow operation in a packed bed FlowSyn microreactor with a GAM II coil-in-coil gas pre-saturator ${ }^{34}$ (Scheme 2); greatly increases the activity and selectivity of $\mathrm{Pt} / \mathrm{SiO}_{2}$ towards the liquid phase hydrogenation of CinnALD to CinnOH, accompanied by dramatically improved catalyst stability and ease of separation and flexible productivity.

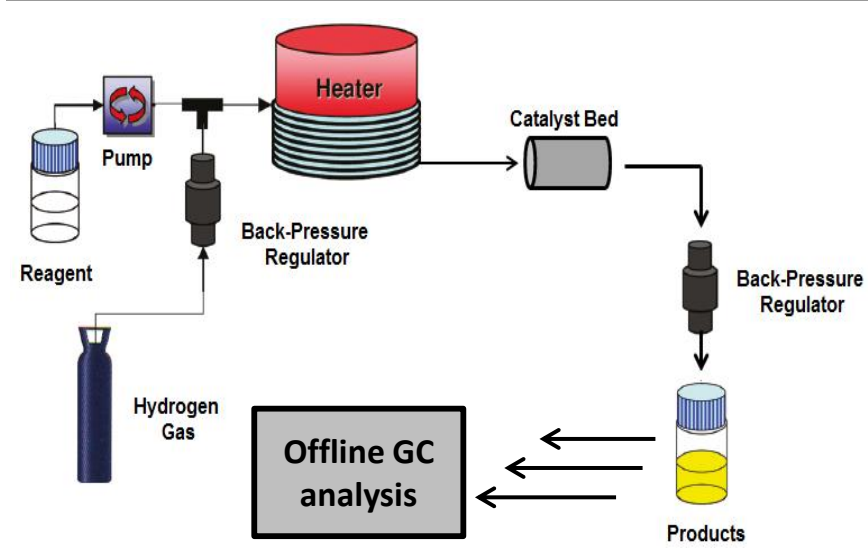

Scheme 2. Schematic of FlowSyn continuous flow reactor for heterogeneously catalysed cinnamaldehyde hydrogenation.

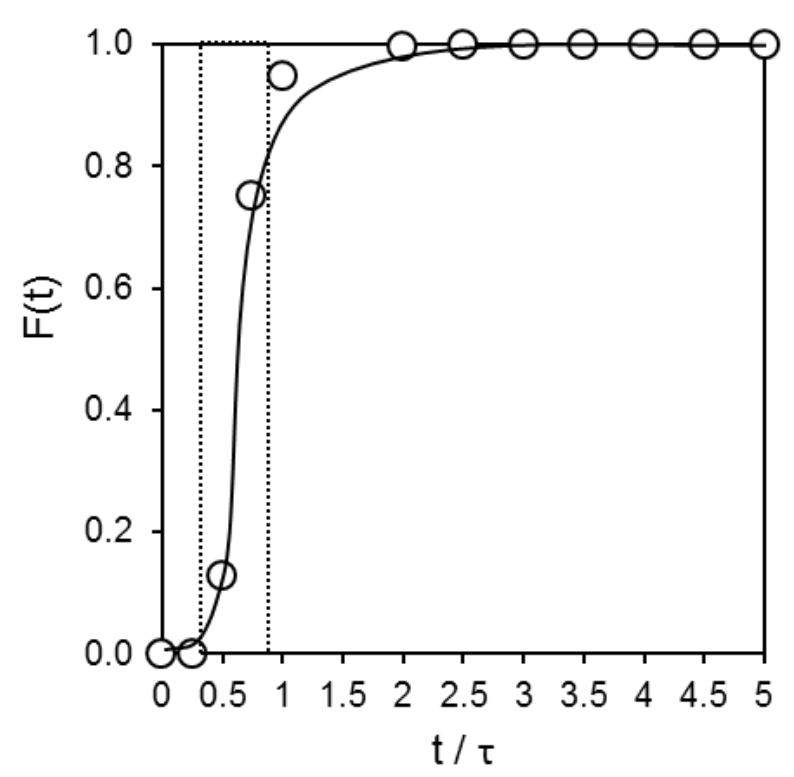

Figure 1. Residence time distribution curve showing the step change response associated with the flow of cinnamaldehyde starting at time $t=0$ through the FlowSyn reactor loaded with $2 \mathrm{wt} \% \mathrm{Pt} / \mathrm{SiO}_{2}$ catalyst. The reaction was monitored by $\mathrm{GC}$, with $F(t)$ indicating the fraction of total [cinnamaldehyde + all products] detected from the reactor outlet as a function of time, and $\tau$ corresponding to the mean residence time (13.86 min). Reaction conditions: $200 \mathrm{mg}$ of $\mathrm{Pt} / \mathrm{SiO}_{2}, 0.08$ to $2.4 \mathrm{~cm}^{3} \cdot \mathrm{min}^{-1}$ liquid flow ( $84 \mathrm{mM}$ in anisole), $40 \mathrm{~cm}^{3}$ hydrogen gas flow at 5 bar and $90^{\circ} \mathrm{C}$.

Structural properties of the wet-impregnated $2 \mathrm{wt} \% \mathrm{Pt} / \mathrm{SiO}_{2}$ catalyst are presented in Table 1 and Figures S1-2. The liquid residence time $\tau$ (defined as bed volume/flow rate) was studied with gas flow through determining the system response to the introduction of cinnamaldehyde. The resulting residence time distribution for the normalised response $F(t)^{35}$ given by Equation 1, showed a step change, and hence near plug-flow behaviour with relatively little broadening from mixing or axial dispersion (Figure 1). This demonstrates that the catalyst bed was static and filled with well-distributed liquid. At 1 bar, CinnALD hydrogenation was first order in catalyst charge under the conditions employed in this study (Table S2), confirming the absence of external mass-transport limitations.

$F(t)=\left\{\left([\operatorname{CinnALD}]_{t}+\left[\right.\right.\right.$ Products $\left.\left.\left._{t}\right]\right) /[\text { CinnALD }]_{\text {inlet }}\right\} / \tau$

The influence of residence time on CinnALD conversion and product selectivity was first investigated (Figure 2 ). At the shortest residence times $(\tau<5 \mathrm{~min})$ only trace CinnALD conversion was observed, consistent with the relatively slow batch kinetics (initial rates of $500 \mathrm{mmol} . \mathrm{g}^{-1} \mathrm{Pt} . \mathrm{h}^{-1}$ ). As the residence time increases, a corresponding monotonic increase in activity was observed, with single pass conversions reaching $45 \%$, however CinnALD hydrogenation attained a plateau at longer residence times above $15 \mathrm{~min}$, likely due to limited hydrogen availability under these conditions; the reaction order in $\mathrm{pH}_{2}$ was 0.5 (Figure S3), in excellent agreement with that reported in batch over supported Pt nanoparticles. Product selectivity exhibited a more complex relationship with 

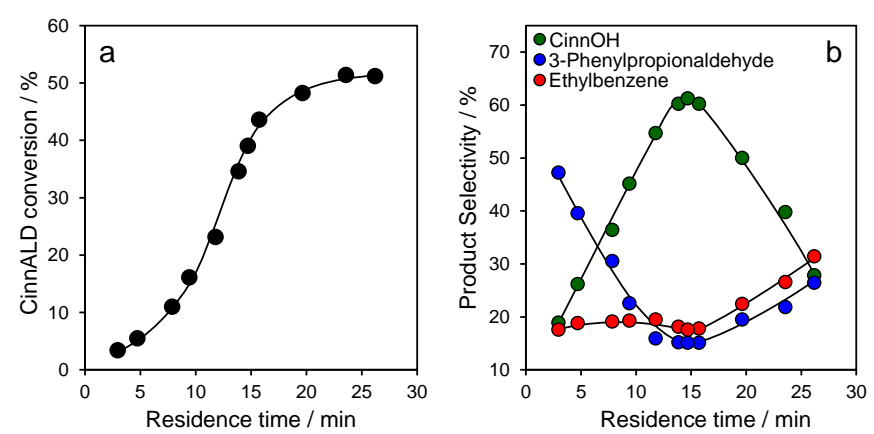

Figure 2. The influence of residence time on (a) CinnALD hydrogenation, and (b) selectivity over $2 \mathrm{wt} \% \mathrm{Pt} / \mathrm{SiO}_{2}$. Reaction conditions: $200 \mathrm{mg}$ of $\mathrm{Pt} / \mathrm{SiO}_{2}$, liquid flow 0.08 to $2.4 \mathrm{~cm}^{3} \cdot \mathrm{min}^{-1}$ ( $84 \mathrm{mM}$ in anisole), $40 \mathrm{~cm}^{3}$ hydrogen gas flow at 5 bar and $90{ }^{\circ} \mathrm{C}$ catalyst.

residence time. CinnOH displayed a volcano dependence, peaking around $60 \%$ for $\tau=15 \mathrm{~min}$, coincident with the maximum rate of CinnALD hydrogenation, and inversely correlated with the formation of undesired 3phenylpropionaldehyde and ethylbenzene products via competing $\mathrm{C}=\mathrm{C}$ hydrogenation and decarbonylation of the resulting saturated aldehyde. Small quantities (3-8 \%) of 3phenyl propanol and cinnamyl cinnamate were also formed, mirroring the variation in 3-phenylpropionaldehyde (Figure S4). These trends are similar to those seen in batch, wherein CinnALD hydrogenation to 3-phenylpropionaldehyde and 3 phenylpropan-1-ol is favoured at conversions $<5 \%$ (the latter a secondary product from rapid hydrogenation of reactivelyformed $\mathrm{CinnOH}$ over $\mathrm{SiO}_{2}$ supported platinum), with selectivity towards $\mathrm{CinnOH}$ increasing to $45 \%$ at $40 \%$ conversion. The fall in $\mathrm{CinnOH}$ selectivity and concomitant rise in 3phenylpropionaldehyde, and ethylbenzene and 3phenylpropan-1-ol (latter shown in Figure S4) secondary products at longer residence times (high conversion) is attributed to a combination of hydrogen starvation and thermodynamically favoured $\mathrm{C}=\mathrm{C}$ hydrogenation. It is immediately apparent that tuning the residence time affords a simple means to regulate $\mathrm{C}=\mathrm{O}$ versus $\mathrm{C}=\mathrm{C}$ hydrogenation
(Figure S5) and hence optimise the $\mathrm{CinnOH}$ productivity at constant $p \mathrm{H}_{2}$ and temperature, and that good conversion and selectivity are achievable even for comparatively short reaction times.

In order to quantitatively benchmark the performance of our 2 wt\% $\mathrm{Pt} / \mathrm{SiO}_{2}$ catalyst in flow versus batch CinnALD hydrogenation, we subsequently conducted extended testing over $7 \mathrm{~h}$ to evaluate catalyst stability and net $\mathrm{CinnOH}$ productivity. Figure 3a reveals striking differences in catalyst activity, with TOFs at least $50 \%$ higher in flow than batch, even during the early stages of reaction. This suggests either that catalyst deactivation is extremely rapid in batch, or that CinnALD hydrogenation in our batch reactor is rate-limited by mass-transport (presumably of hydrogen). The former appears more plausible, since mixing in stirred batch reactors is known to be highly efficient, and furthermore significant deactivation was subsequently observed over the course of $7 \mathrm{~h}$, occurring at an approximately exponential rate which can be extrapolated back to a similar maximum TOF $=1300 \mathrm{~h}^{-1}$ at zero time as observed in flow; exponential activity decay due to catalyst poisoning by strongly bound products has been previously observed in the (semi-)batch hydrogenation of $\alpha$ methylethylbenzene ${ }^{36}$ and sitosterol ${ }^{37}$ over commercial $\mathrm{Pd} / \mathrm{C}$ catalysts. In contrast, negligible deactivation of the $\mathrm{Pt} / \mathrm{SiO}_{2}$ catalyst was observed in flow, consistent with the rapid removal of reactively-formed products and low attendant concentration of potential poisons. The different time-onstream activity profiles in flow versus batch are mirrored by their corresponding product distributions (Figure $3 \mathbf{b}-\mathbf{c}$ ). In flow, the desired $\mathrm{CinnOH}$ is the major product throughout the course of reaction, with 3-phenylpropionaldehyde and ethylbenzene formed in equal concentrations along with trace and 3-phenylpropan-1-ol, evidencing $\mathrm{C}=\mathrm{O}$ hydrogenation as the dominant primary reaction of CinnALD. Strong timedependent selectivity variations are observed under batch conditions, with the fresh catalyst strongly favouring $\mathrm{C}=\mathrm{C}$ hydrogenation of CinnALD to 3-phenylpropionaldehyde and
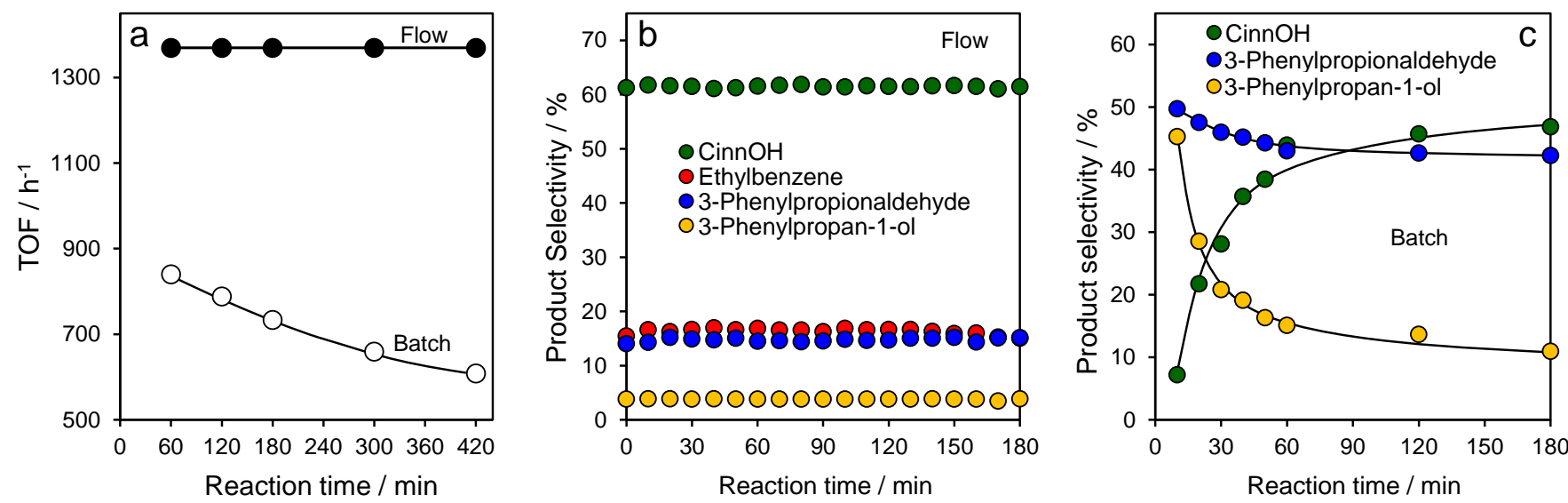

Figure 3. (a) Activity towards CinnALD hydrogenation, and product distributions in (b) flow and (c) batch as a function of time-on-stream over 2 wt\% $\mathrm{Pt} / \mathrm{SiO}_{2}$. Reaction conditions: $200 \mathrm{mg}$ of $\mathrm{Pt}_{\mathrm{SiO}}, 5$ bar $\mathrm{H}_{2}$ and $90{ }^{\circ} \mathrm{C}$ (batch and flow); liquid flow $0.11 \mathrm{~cm}^{3} \cdot \mathrm{min}^{-1}$ (84 mM in anisole), 40 cm hydrogen (flow). 
3-phenylpropan-1-ol; we have previously shown the latter secondary product only arises via hydrogenation of reactivelyformed $\mathrm{CinnOH}$. On-stream catalyst deactivation coincides with a dramatic loss in 3-phenylpropan-1-ol and concomitant rise in selectivity to $\mathrm{CinnOH}$, confirming their interrelationship, and small decrease in 3-phenylpropionaldehyde formation.

The coincidence of deactivation and suppression of $\mathrm{C}=\mathrm{C}$ hydrogenation pathways in batch, strongly implicates a unique $\mathrm{Pt}$ active site responsible for $\mathrm{C}=\mathrm{C}$ hydrogenation, discrete from that catalysing $\mathrm{C}=\mathrm{O}$ hydrogenation. This hypothesis meshes perfectly with our previous studies on size-controlled $\mathrm{Pt}$ nanoparticles over silica supports, wherein low coordination sites prevalent on smaller particles were observed to promote $\mathrm{C}=\mathrm{C}$ hydrogenation of CinnALD, while larger particles and associated $\mathrm{Pt}$ terrace promoted $\mathrm{C}=\mathrm{O}$ hydrogenation. It is wellestablished in heterogeneous catalysts that edge and vertex sites of transition metal particles are highly reactive due to their undercoordination, and (consequentially) prone to selfpoisoning due to the higher adsorption energies of atomic and molecular reactants/products at these sites relative to closepacked facets. Extended Hückel calculations by Delbecq and Sautet have shown that stepped surfaces favour $\pi_{\mathrm{C}=\mathrm{C}}$ CinnALD adsorption modes and $\mathrm{C}=\mathrm{C}$ hydrogenation relative to $\mathrm{Pt}(111)$ terraces which favour di- $\sigma_{c o}$ CinnALD adsorption and $\mathrm{C}=\mathrm{O}$ hydrogenation. ${ }^{38}$ We therefore propose that during batch CinnALD hydrogenation, one or more reactively-formed products associated with $\mathrm{C}=\mathrm{C}$ hydrogenation at reactive, low coordination sites is strongly adsorbed over the sites responsible for its formation, resulting in self-poisoning of $\mathrm{C}=\mathrm{C}$ hydrogenation pathways. Comparison of the flow versus batch product distributions suggests ethylbenzene as the frontrunner candidate poison, it being formed at low concentrations in flow, but rapidly swept away from the catalyst bed minimising the time for its readsorption/equilibration. The absence of ethylbenzene within the bulk reaction media during batch, over the same catalyst to that which forms trace ethylbenzene under identical reaction conditions of temperature, $p \mathrm{H}_{2}$ and [CinnALD] in flow, supports the proposal that catalyst poisoning in batch may reflect adsorption of reactively-formed ethylbenzene over long contact times. The absolute $\mathrm{CinnOH}$ productivity of our $2 \mathrm{wt} \%$ $\mathrm{Pt} / \mathrm{SiO}_{2}$ catalyst in flow versus batch is compared in Figure 4, which highlights an approximately constant four-fold yield enhancement for CinnALD hydrogenation under flow.

\section{Conclusions}

The transition from liquid phase batch to continuous flow cinnamaldehyde hydrogenation over a $\mathrm{Pt} / \mathrm{SiO}_{2}$ heterogeneous catalysts affords significant enhancements in activity and selectivity towards $\mathrm{C}=\mathrm{O}$ activation under optimised (mild) reaction conditions of 5 bar and $90{ }^{\circ} \mathrm{C}$. Superior catalytic performance in flow is attributed to removal of the reactivelyformed cinnamyl alcohol and 3-phenylpropionaldehyde primary products from the reaction zone, limiting their overhydrogenation and/or hydrogenolysis to 3-phenylpropan-1-ol

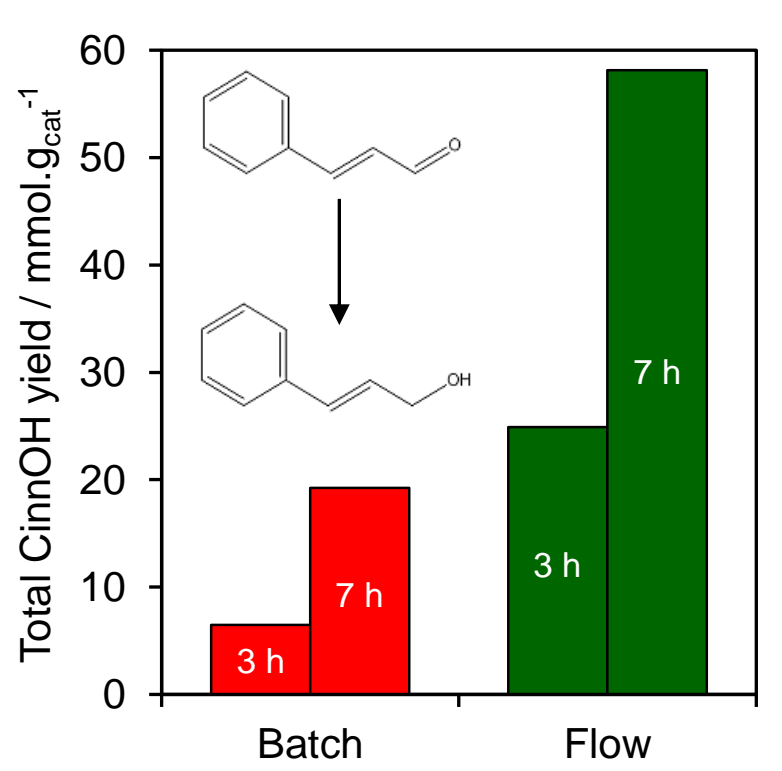

Figure 4. Cumulative $\mathrm{CinnOH}$ yield after $3 \mathrm{~h}$ and $7 \mathrm{~h}$ CinnALD hydrogenation over $2 \mathrm{wt} \%$ $\mathrm{Pt} / \mathrm{SiO}_{2}$. Reaction conditions: $200 \mathrm{mg}$ of $\mathrm{Pt} / \mathrm{SiO}_{2}, 5$ bar $\mathrm{H}_{2}$ and $90{ }^{\circ} \mathrm{C}$ (batch and flow); liquid flow $0.11 \mathrm{~cm}^{3} \cdot \mathrm{min}^{-1}$ ( $84 \mathrm{mM}$ in anisole) and $40 \mathrm{~cm}^{3}$ hydrogen (flow).

and ethylbenzene which are implicated as strongly adsorbing catalyst poisons under batch operation. The combination of excellent catalyst activity, stability and good selectivity in continuous flow deliver (predictable) cumulative cinnamyl alcohol productivities four times greater than possible under comparable conditions in batch.

\section{Acknowledgements}

We thank the EPSRC for financial support (EP/G007594/4 and EP/K014749/1) and the award of a Leadership Fellowship to AFL. KW thanks the Royal Society for an Industry Fellowship.

\section{Notes and references}

1. G. A. Somorjai and K. McCrea, Applied Catalysis A: General, 2001, 222, 3-18.

2. G. A. Somorjai, H. Frei and J. Y. Park, Journal of the American Chemical Society, 2009, 131, 16589-16605.

3. B. M. Trost and R. J. Kulawiec, Journal of the American Chemical Society, 1993, 115, 2027-2036.

4. B. Breit and W. Seiche, Synthesis, 2001, 1-36.

5. K. W. Fiori and J. Du Bois, Journal of the American Chemical Society, 2007, 129, 562-568.

6. J. Magano and J. R. Dunetz, Organic Process Research \& Development, 2012, 16, 1156-1184.

7. H. U. Blaser, H. Steiner and M. Studer, ChemCatChem, 2009,

1, 210-221.

8. R. A. Sheldon, Green Chemistry, 2014, 16, 950-963.

9. P. Gallezot and D. Richard, Catalysis Reviews, 1998, 40, 81126. 
10. H. U. Blaser, C. Malan, B. Pugin, F. Spindler, H. Steiner and M. Studer, Adv. Synth. Catal., 2003, 345, 103-151.

11. P. Maki-Arvela, J. Hajek, T. Salmi and D. Y. Murzin, Appl. Catal. A-Gen., 2005, 292, 1-49.

12. I. Lee, F. Delbecq, R. Morales, M. A. Albiter and F. Zaera, Nat Mater, 2009, 8, 132-138.

13. G. A. Attard, J. A. Bennett, I. Mikheenko, P. Jenkins, S. Guan, L. E. Macaskie, J. Wood and A. J. Wain, Faraday Discussions, 2013, 162, 57-75.

14. C. Poupin, R. Maache, L. Pirault-Roy, R. Brahmi and C. T. Williams, Applied Catalysis A: General, 2014, 475, 363-370.

15. P. Lara, A. Suárez, V. Collière, K. Philippot and B. Chaudret, ChemCatChem, 2014, 6, 87-90.

16. L. A. Saudan, Accounts of Chemical Research, 2007, 40, 13091319.

17. J. A. Maga, Crc Critical Reviews in Food Science and Nutrition, 1978, 10, 323-372.

18. C. S. Letizia, J. Cocchiara, J. Lalko, A. Lapczynski and A. M. Api, Food and Chemical Toxicology, 2005, 43, 837-866.

19. D. A. Buckley, British Journal of Dermatology, 2007, 157, 295300.

20. M. A. Vannice and B. Sen, Journal of Catalysis, 1989, 115, 65-

78.

21. W. O. Oduro, N. Cailuo, K. M. Yu, H. Yang and S. C. Tsang, Physical chemistry chemical physics : PCCP, 2011, 13, 2590-2602. 22. S. C. Tsang, N. Cailuo, W. Oduro, A. T. S. Kong, L. Clifton, K. M. K. Yu, B. Thiebaut, J. Cookson and P. Bishop, ACS Nano, 2008, 2, 2547-2553.

23. Y. Zhu and F. Zaera, Catalysis Science \& Technology, 2014, 4, 955-962.

24. Z. Guo, C. Xiao, R. V. Maligal-Ganesh, L. Zhou, T. W. Goh, X. Li, D. Tesfagaber, A. Thiel and W. Huang, ACS Catalysis, 2014, 1340-1348

25. X. Ji, X. Niu, B. Li, Q. Han, F. Yuan, F. Zaera, Y. Zhu and H. Fu, ChemCatChem, 2014, n/a-n/a.

26. L. J. Durndell, C. M. A. Parlett, N. S. Hondow, M. A. Isaacs, K. Wilson and A. F. Lee, Sci. Rep., 2015, 5.

27. M. Irfan, T. N. Glasnov and C. O. Kappe, ChemSusChem, 2011, 4, 300-316.

28. X. Liu, B. Unal and K. F. Jensen, Catalysis Science \& Technology, 2012, 2, 2134-2138.

29. X. Ye, M. D. Johnson, T. Diao, M. H. Yates and S. S. Stahl, Green Chemistry, 2010, 12, 1180-1186.

30. C. Wiles and P. Watts, Green Chemistry, 2012, 14, 38-54.

31. L. Vaccaro, D. Lanari, A. Marrocchi and G. Strappaveccia, Green Chemistry, 2014, 16, 3680-3704.

32. A. Müller, M. Ludwig, M. Arlit and R. Lange, Catalysis Today, 2015, 241, Part B, 214-220.

33. N. M. Islam, M. Chatterjee, Y. Ikushima, T. Yokoyama and H. Kawanami, International Journal of Molecular Sciences, 2010, 11, 164-172.

34. M. O'Brien, N. Taylor, A. Polyzos, I. R. Baxendale and S. V. Ley, Chemical Science, 2011, 2, 1250-1257.

35. D. S. Mannel, S. S. Stahl and T. W. Root, Organic Process Research \& Development, 2014, 18, 1503-1508.

36. H.-S. Phiong, C. G. Cooper, A. A. Adesina and F. P. Lucien, The Journal of Supercritical Fluids, 2008, 46, 40-46.
37. T. Salmi, D. Y. Murzin, J. Wärnå, P. Mäki-Arvela and G. Martin, Chemical Engineering Science, 2013, 104, 156-165. 38. F. Delbecq and P. Sautet, Journal of Catalysis, 1995, 152, 217-236. 